\title{
A Study to Investigate Major Community Health Challenges and Their Predisposing Factors in Bushenyi District of South Western Uganda
}

\author{
Isaac Echoru ${ }^{*}$, Keneth Iceland Kasozi ${ }^{2}$, Emmanuel Tiyo Ayikobua ${ }^{2}$, Simon Peter Emorut ${ }^{3}$ \\ ${ }^{1}$ Department of Anatomy, Faculty of Biomedical Sciences, Kampala International University Western Campus, \\ Bushenyi, Uganda \\ ${ }^{2}$ Department of Physiology, Faculty of Biomedical Sciences, Kampala International University Western Campus, \\ Bushenyi, Uganda \\ ${ }^{3}$ Department of Public Health, Faculty of Allied Health sciences, Kampala International University Western \\ Campus, Bushenyi, Uganda \\ Email: ${ }^{*}$ echoruisaac@gmail.com
}

Received 22 January 2015; accepted 30 March 2015; published 7 April 2015

Copyright @ 2015 by authors and Scientific Research Publishing Inc.

This work is licensed under the Creative Commons Attribution International License (CC BY).

http://creativecommons.org/licenses/by/4.0/

(c) (i) Open Access

\section{Abstract}

Poor health care systems have contributed to poor standard of living in Uganda. The aim of the study was to assess major health challenges to community health and identify major predisposing factors. This was a cross sectional study in Kyakagina Village of Bushenyi of South Western Uganda. $A$ total of 39 households which included 102 children ( $<19$ years) and 80 adults ( $>19$ years) were included in the study and a semi structured questionnaire was used. It was shown that there were 39 homes and 182 members with more males than females. Age and gender were shown not to be associated $(P=0.157)$. The majority of participants who boiled water in the community were showed to be of both primary and secondary level of education at $48.7 \%$ and $51.3 \%$, respectively, while a significant proportion was found to drink only filtered and sedimented water without treatment at levels of $87.2 \%$ and $82.1 \%$ who were of only secondary level of education. The adoption of modern contraceptive pills, tube ligation and injections especially amongst the secondary educated level was found to be high, i.e. $94.9 \%, 87.2 \%, 82.1 \%$, respectively. Inferential analysis showed that there existed marked differences $(P<0.001)$ in the health practices between persons of different education levels. Major health challenges identified included malaria, cough and cold, diarrhea which were most prevalent amongst children at $19.6 \%, 13.7 \%$, and $10.8 \%$, respectively. In conclusion, failure to clear bushes, boil drinking water and cover pit latrines $(P=0.213)$ were

\footnotetext{
${ }^{*}$ Corresponding author.
} 
the major risk factors identified independent of age and education status in the various homesteads.

\title{
Keywords
}

\author{
Community Health Challenges in Uganda, Community Health in Western Uganda, Public Health \\ Uganda
}

\section{Introduction}

Uganda is faced with a couple of health extension service challenges and one of the hindrances to further development both socially and economically in most developing countries like Uganda is probably due to poor health that people in rural communities are constantly exposed to, thus lowering their standards of living inevitably [1]. These challenges come as a result of disease burden that originate from poor health practices which are further complicated by the low levels of literacy in the communities [2]. School going children in these communities tend to experience interruptions in their academic studies and household propagated illnesses are thought to be major contributors to this problem [3]. This has been shown to subsequently lead to limited and poor individual academic progress, thus being a major contributor to the high school dropout rates in several rural communities and the observed limited progress of the universal primary education (UPE) programme in Uganda [2]-[4]. The World Health Organization (WHO) recommends the usage of community health workers at the community level for better management of health challenges like malaria and pneumonia through community case management due to the severe human resource challenges in the Africa continent [1]. Epidemiological studies have shown that children $(<5$ years) are most predisposed to illnesses like malaria, diarrhea, and pneumonia as they have been shown to be associated with poor community health and hygiene [1] [2]. Challenges to health practices have been associated with malnutrition in children [3], low socioeconomic status and high illiteracy rates in mothers [4], lack of safe drinking-water, poor sanitation and hygiene [5], increasing population growth and high incidence of young mothers ( $<18$ years) [6]. This has subsequently contributed greatly to the low progress in development of the rural communities at both socio-economic and health levels [7]. Due to the prevailing poor hygienic conditions in these communities, gastrointestinal parasites have been identified at high prevalence levels, and strong associations with socio-economic and community health practices have been demonstrated [8]. Studies have further shown that the majority $(\geq 85 \%)$ of the Sub-Saharan African population still suffer from preventable diseases through poor hygienic practices, thus most of the mortalities witnessed in the $21^{\text {st }}$ century would totally be avoided especially amongst children [9]. The increasing incidence of gastrointestinal diseases raises major concerns on community hygiene and waste management, which have also continued to be major challenges for the local authorities in developing countries due to the high rate of waste accumulation amidst a dysfunctional decentralized local government in several communities [10] [11].

The local government in Kampala (Uganda) has endeavored to educate and actively get involved in helping communities work on their general health; however, major challenges on the appropriate methods on waste management and recycling still exist, thus leading to limited progress on this subject in the region and children have been reported to be the major victims in disease outbreaks [1] [2] [12] [13]. These weaknesses in the national efforts to promote community health have subsequently led to the creation of new habitats for various disease vectors, and foremost of these are malaria and intestinal infections [14] [15]. The above factors clearly show that communities face major health challenges that are often neglected or never identified for integrative national planning [16]. Several factors are believed to play crucial roles in the poor adoption of national programs in different rural communities, but the major predisposition factor has been established to be the limited human resource of medical staff in rural communities [17]. This study was carried out to assess the major health challenges and identify any associated risk factors in a rural community of South Western Uganda.

\section{Materials and Methods}

This was a cross sectional study carried out in a rural community of Kyakagina Village in Bushenyi District of South Western Uganda for a period of five months (January to May 2014). Participants in the study were resi- 
dents from Kyakagina village and a total of 39 households which included 102 children ( $<19$ years) and 80 adults ( $>19$ years) were included in the study, who were chosen randomly. The study consisted of 40 homesteads. From the homes selected, consent was sought from the family head and members of the family that were available, data was collected and recorded according to gender and age i.e. children ( $<19$ years) and adults ( $>19$ years) and all members who were visitors of less than one month were excluded from the study. Household information was collected through a structured questionnaire which was administered to the homesteads and information on health related challenges, waste management, family planning, nutrition, sanitataion was collected. On site observations were made to validate responses on the data collection tool. Data was recorded as frequencies, expressed as percentages, and analysis carried out using SPSS version 21 to determine group associations of educational standards and the associated risk factors. Statistical analysis was done and significance was reported at $\mathrm{P} \leq 0.05$.

\section{Results}

There were 182 respondents of which 102 were children and 80 were adults. It was shown that there were more males than females as shown in Table 1. Age and gender were shown not to be associated $(P=0.157)$. Out of the 39 homes in the study, most members were farmers (59\%) as shown in Table 2. It was also shown that the major level of education in the community was at primary level (51.3\%) followed by secondary school level as shown in Table 3. No significant relationship $(\mathrm{P}=0.213)$ was shown to exist between secondary and primary school leavers in comparison to those that did not attend any school. Out of 39 homes from the study, mulching and burning were identified as major means of solid waste management with frequencies of $46.2 \%, 53.8 \%$ and $33.3 \%$ and $66.7 \%$ respectively in homes falling under primary and secondary school level of education category.

Table 1. Showing gender and age in the study area.

\begin{tabular}{ccc} 
& \multicolumn{2}{c}{ Gender } \\
\cline { 2 - 3 } Age & \multicolumn{2}{c}{ Frequency (\%) } \\
\cline { 2 - 3 } & Males & Females \\
\hline Children & $55(30.2)$ & $47(25.2)$ \\
Adults & $38(20.9)$ & $42(20.1)$ \\
\hline
\end{tabular}

Table 2. Showing occupation of participants in the study area. Further analysis, $\mathrm{P} \leq 0.199$.

\begin{tabular}{|c|c|c|c|}
\hline \multirow{2}{*}{ Parameter } & \multirow{2}{*}{ Variables } & Positive & Negative \\
\hline & & \multicolumn{2}{|c|}{ Frequency (\%) } \\
\hline \multirow{3}{*}{ Occupation } & Peasant farmers & $23(59)$ & $16(41)$ \\
\hline & Business & 14 (35.9) & $25(64.1)$ \\
\hline & Civil service & $02(5.1)$ & 37 (94.9) \\
\hline
\end{tabular}

Table 3. Showing levels of education in the study area.

\begin{tabular}{cccc}
\hline \multirow{2}{*}{ Parameter } & Variable & Positive & Negative \\
\cline { 3 - 4 } & Primary & $41(51.3)$ & $39(48.7)$ \\
Level of education & Secondary & $26(32.5)$ & $54(67.5)$ \\
& Tertiary & $03(3.8)$ & $77(96.2)$ \\
& None & $10(12.5)$ & $70(87.5)$ \\
\hline
\end{tabular}


Majority of participants in both levels of education boiled water for drinking i.e. $48.7 \%$ and $51.3 \%$ respectively while a significant proportion among the secondary level category was found to drink water that was filtered and sedimented i.e. $87.2 \%$ and $82.1 \%$ respectively as shown in Table 4 . Inferential analysis showed there existed marked differences $(\mathrm{P}<0.001)$ in the health practices between persons of different education levels. Soak pits were often used for waste water or sewage water drainage by a group of participants majorly in the category of secondary level education (84.6\%) and the nutritional status in children were found to be good $(74.4 \%)$ in the secondary school level of education category compared to those in primary level category (25.6\%). The most practice family method among the primary school level category was natural method (withdrawal) with 46.2\% well as $94.9 \%$ and $87.2 \%$ practiced tube legation and use of pills respectively. Majority of the unclean toilets were found to be in homesteads of participants who had attained at least a secondary level of education (61.1\%) compare to $38.9 \%$ among those who had attained a primary level education. About $75 \%$ and $25 \%$ of the study homes had hand washing facilities i.e. secondary versus primary level of education respectively and $66.7 \%$ of the homes in secondary level kept their bird shelter in their kitchens as compared to $33 \%$ from primary level of education who had separate animal and bird house as shown in Table 4. The major health challenge was malaria, cough and cold, diarrhea especially in children at $19.6 \%, 13.7 \%$, and $10.8 \%$ respectively as shown in Table 5 . Further analysis showed there existed no significant differences $(P=0.213)$ in the community illnesses in both

\begin{tabular}{|c|c|c|c|}
\hline \multirow{2}{*}{ Parameter } & \multirow{2}{*}{ Variable } & Primary level & Secondary level \\
\hline & & \multicolumn{2}{|c|}{ Frequency (\%) } \\
\hline \multirow[t]{4}{*}{ Solid waste management } & Refuse pit & $8(20.5)$ & 31 (79.5) \\
\hline & Mulching & $18(46.2)$ & $21(53.8)$ \\
\hline & Burning & $13(33.3)$ & $26(66.7)$ \\
\hline & Burying & $0(0)$ & $39(100)$ \\
\hline \multirow[t]{2}{*}{ Soak pit } & Present & $6(15.4)$ & $33(84.6)$ \\
\hline & Absent & $33(84.6)$ & $6(15.4)$ \\
\hline \multirow[t]{4}{*}{ Water purification } & Boiling & 19 (48.7) & $20(51.3)$ \\
\hline & Add chemical & $1(2.6)$ & 38 (97.4) \\
\hline & Filter & $12(30.8)$ & $27(87.2)$ \\
\hline & Sedimentation & $7(17.9)$ & $32(82.1)$ \\
\hline \multirow[t]{4}{*}{ Family planning } & Tubal ligation & $2(5.1)$ & 37 (94.9) \\
\hline & Pills & $12(30.8)$ & $38(87.2)$ \\
\hline & Injections & $7(17.9)$ & $32(82.1)$ \\
\hline & Natural & $18(46.2)$ & $21(53.8)$ \\
\hline \multirow[t]{2}{*}{ Nutrition (children) } & Good & $10(25.6)$ & $29(74.4)$ \\
\hline & Fair & $10(25.6)$ & $29(74.4)$ \\
\hline \multirow[t]{2}{*}{ Condition of pit latrines } & Clean & $25(64.1)$ & 14 (35.9) \\
\hline & Not clean & 14 (38.9) & $25(61.1))$ \\
\hline \multirow[t]{2}{*}{ Hand washing practices } & Present & $10(25.6)$ & $29(74.4)$ \\
\hline & Absent & $29(74.4)$ & $10(25.6)$ \\
\hline \multirow[t]{2}{*}{ Animal and bird shelter } & Kitchen & $13(33.3)$ & $26(66.7)$ \\
\hline & Separate & $26(66.7)$ & $13(33.3)$ \\
\hline
\end{tabular}


children and adults. It was shown that community members who had a higher level of education sort health advice from clinics, traditional healer, and health centers at $94.9 \%, 97.4 \%$, and $79.5 \%$ respectively as shown in Table 6. The study showed that members in the community were not actively involved in community activities that promote health with their neighbors as shown in Table 7.

\section{Discussion}

Majority of the study participants in the homesteads were of the male gender as shown in Table 1. Age and gender were shown not to be associated $(\mathrm{P}=0.157)$. This would probably be because of the community cultural values were men are freely allowed to talk to strangers ("researchers"), while women are forced to keep a silent mouth. This generally shows that considerable gender inequality issues still stand strong in this rural community [3] [4]. It was also observed the majority of the women never completed their education careers thus affirming that the rate of school dropouts, and maginalization of the girl child still stand strong in a couple of rural communities in the $21^{\text {st }}$ centrury [2] [3]. Poverty and lack of family support were identified as the major predisposition factors to the failure of the community members to proceed with secular education. This further highlights the major challenges currently facing the UPE programme nationwide [4] [6].

Despite of the high levels of poverty in the community, several homesteads were found to be actively involved in a couple of commercial activities such as dairy farming, plantation agriculture (growing bananas on large scale) and a few members were sole proprietors. The commercial businesses were solely observed to be

\begin{tabular}{lccc}
\hline \multirow{2}{*}{ Table 5. Showing common illness in the study area. } & \multicolumn{1}{c}{ Children } & \multicolumn{2}{c}{ Adults } \\
\hline \multirow{2}{*}{ Parameter } & Variable & \multicolumn{2}{c}{ Frequency (\%) } \\
\cline { 3 - 4 } & Malaria & $20(19.6)$ & $20(25)$ \\
Cough and cold & $14(13.7)$ & $6(7.5)$ \\
& Hypertension & $0(0)$ & $1(1.3)$ \\
& Diarrhea & $11(10.8)$ & $4(5)$ \\
& Skin disease & $6(5.9)$ & $3(3.8)$ \\
\hline
\end{tabular}

Table 6. Showing health seeking behaviors in the study area.

\begin{tabular}{cccc}
\hline \multirow{2}{*}{ Parameter } & Variables & Primary level & Secondary level \\
\cline { 3 - 4 } & & \multicolumn{2}{c}{ Frequency (\%) } \\
\hline \multirow{3}{*}{ Health management } & Drug shop & $28(71.8)$ & $11(28.2)$ \\
& Clinic & $2(5.1)$ & $37(94.9)$ \\
\cline { 3 - 4 } & Traditional healer & $1(2.6)$ & $38(97.4)$ \\
& Health center & $8(20.5)$ & $31(79.5)$ \\
\hline
\end{tabular}

Table 7. Showing general community work participation by adults.

\begin{tabular}{cccc}
\hline \multirow{2}{*}{ Parameter } & Variable & Yes & No \\
\cline { 3 - 4 } & Cleaning water source & $22(27.5)$ & $58(72.5)$ \\
\hline \multirow{2}{*}{$\begin{array}{c}\text { General community } \\
\text { work }\end{array}$} & Cleaning market & $15(18.8)$ & $65(81.2)$ \\
& Clearing bushes & $31(38.9)$ & $49(61.2)$ \\
& Clearing roads & $12(15)$ & $68(85)$ \\
\hline
\end{tabular}


owned by men and women kept to the farming and household duties due to their gender. Recent changes in climate and loss of soil fertility were secondary factors to the decreased productivity of the farming enterprises (primary data). Participants of different education level were shown to exhibit different levels of household hygiene $(\mathrm{P}<0.001)$. This could probably be due to the fact that individuals who had the opportunity to gain a higher education were relatively more educated and appreciated the benefits of preventive approaches to disease, thus continously serving as module households in this community [7].

The study also revealed that the major waste management approach in the homesteads were mulching for bio-degradable solid wastes like banana peeling, banana leaves and animal waste so as to keep the soil fertile for agriculture [18]. Burning of dry banana leaves from the plantations was the second most used method probably because it was considered to be less costly; however some homes were reluctant to practice it due to the accumulation of smoke which pollutes the environment and predisposes family members to respiratory infections [19]. Refuse pits were not common (79.5\%) in the community households visited. This could probably be because community members believed they were time consuming and costly to dig. Waste water generated was mainly from washing of clothes, utensils and bathrooms, lack of soak pits from most homes was because of inadequate technical know-how, laziness and absence of sewage water recycling mechanisms in place. Most of the homes purified drinking water mainly by boiling water which was ideal however there were some cases of diarrhea registered whose cause may have be linked to poor hygiene [6] [9]. Assessment of household hygiene showed that most of the homesteads which had pit latrines, had a challenge of poor hygiene which would probably be due to the high illiteracy levels on appropriate methods $f$ hygiene and waste management [20]. Majority of the homesteads had flies within the house, which indicated increased risk of infection to gastrointestinal disease. These were considered to be major vectors for disease transmission especially amongst children and mothers who are often at home [12] [13]. Most families practiced natural methods of family planning while a minority $(<30 \%)$ had attempted to adopt the usage of secular family planning approaches [16] [17]. We also discovered that women who were using commercial contraceptive methods were well known in the community probably as a result of the extension service delivery from neighboring medical facilities in the region especially from Kampala International University Teaching Hospital (KIU-TH). This approach would probably help reduce on the stigma and illiteracy on the available methods on birth control, thus working as a synergy for a couple of government and private organizational programmes [17].

The major health challenges identified in this community were malaria, cough, cold and diarrhea and poor nutrition, and all these being most prevalent amongst infants and children. These findings are in agreement with previous studies that children are the greatest exposed population to disease in the management of community health [1] [2]. Further analysis showed there existed no significant differences $(P=0.213)$ in the community illnesses in both children and adults, thus efforts to control and manage infectious diseases such as malaria in rural communities should target persons of all age groups, despite of the fact that children have been identified as the vulnerable population [2]. The low coverable and poor hygienic status of the pit latrines was primarily due to the low level of education, thus extension service delivery in the rural communities to improve on community knowledge regarding waste management and disposal would help to increase on community awareness in this sector [12].

\section{Conclusion and Recommendations}

This study showed that the majority of homesteads continuously face primary health challenges that would otherwise be averted through increased sensitization and promotion of socio-economic activities to improve on individual livelihoods. This would ultimately help communities live healthier happy lives, with improved standards of living and realization of the millennial developmental goals (MDGs). Several stake holders in the health sector should work in partnership to serve and help the vulnerable communities in our societies.

\section{Acknowledgements}

The authors would like to extend their appreciation to the support that was offered by the local government of Kyakagina Village and above all the community members who participated thus making this study a success. We also thank the local community participants who welcomed and allowed us to carry out this work in their homesteads, the local chairperson of the village, and above all, the community education coordination office of Kampala International University Western Campus, Bushenyi, Uganda that supported the study. 


\section{Authors Contributions}

S.P.E., designed the study, I.E., wrote the first draft of the manuscript and S.P.E coordinated all the fieldwork. K.I.K., and I.E., managed the literature searches and I.E., K.I.K., and E.T.A., managed data analyses of the study. The final version of this manuscript was reviewed and approved by all authors prior to submission.

\section{Ethical Considerations}

Authors hereby declare the study was approved by the appropriate ethics committee and have therefore been performed in accordance with the ethical standards laid down in the 1964 Declaration of Helsinki.

\section{Competing Interests}

The authors declare there exist no competing interests.

\section{References}

[1] WHO/UNICEF (2004) WHO/UNICEF Joint Statement: Management of Pneumonia in Community Settings. World Health Organization, Geneva.

[2] Bagonza, J., Kibira, S.P.S. and Rutebemberwa, E. (2014) Performance of Community Health Workers Managing Malaria, Pneumonia and Diarrhoea under the Community Case Management Programme in Central Uganda: A Cross Sectional Study. Malaria Journal, 13, 367. http://dx.doi.org/10.1186/1475-2875-13-367

[3] Müller, O. and Krawinkel, M. (2005) Malnutrition and Health in Developing Countries. Canadian Medical Association Journal, 173, 279-286. http://dx.doi.org/10.1503/cmaj.050342

[4] Amuna, P. and Zotor, F.B. (2008) Epidemiological and Nutrition Transition in Developing Countries: Impact on Human Health and Development. The Proceedings of the Nutrition Society, 67, 82-90. http://dx.doi.org/10.1017/S0029665108006058

[5] Montgomery, M.A., Bartram, J. and Elimelech, M. (2009) Increasing Functional Sustainability of Water and Sanitation Supplies in Rural Sub-Saharan Africa. Environmental Engineering Science, 26, 1017-1023. http://dx.doi.org/10.1089/ees.2008.0388

[6] Agustina, R., Sari, T.P., Satroamidjojo, S., Bovee-oudenhoven, I.M.J., Feskens, E.J.M. and Kok, F.J. (2013) Association of Food-Hygiene Practices and Diarrhea Prevalence among Indonesian Young Children from Low Socioeconomic Urban Areas. BMC Public Health, 13, 1. http://dx.doi.org/10.1186/1471-2458-13-977

[7] Basu, S., Andrews, J., Kishore, S., Panjabi, R. and Stuckler, D. (2012) Comparative Performance of Private and Public Healthcare Systems in Low- and Middle-Income Countries: A Systematic Review. PLoS Medicine, 9, e1001244. http://dx.doi.org/10.1371/journal.pmed.1001244

[8] Kipyegen, C.K., Shivairo, R.S. and Odhiambo, R.O. (2012) Prevalence of Intestinal Parasites among HIV Patients in Baringo, Kenya. The Pan African Medical Journal, 13, 37.

[9] Cairncross, S., Hunt, Ã.C., Boisson, S., Bostoen, K., Curtis, V., Fung, I.C.H. and Schmidt, W.-P. (2010) Water, Sanitation and Hygiene for the Prevention of Diarrhoea. International Journal of Epidemiology, 39, i193-i205. http://dx.doi.org/10.1093/ije/dyq035

[10] Guerrero, L.A., Maas, G. and Hogland, W. (2013) Solid Waste Management Challenges for Cities in Developing Countries. Waste Management, 33, 220-232. http://dx.doi.org/10.1016/j.wasman.2012.09.008

[11] Imam, A., Mohammed, B., Wilson, D.C. and Cheeseman, C.R. (2008) Solid Waste Management in Abuja, Nigeria. Waste Management, 28, 468-472. http://dx.doi.org/10.1016/j.wasman.2007.01.006

[12] Ssempebwa, J.C. and Carpenter, D.O. (2010) The Generation, Use and Disposal of Waste Crankcase Oil in Developing Countries: A Case for Kampala District, Uganda. Journal of Hazardous Materials, 161, 835-841.

[13] Jukes, M. (2007) Impact of Early Childhood Health and Nutrition on Access to Education in Developing Countries. Paediatrics and Child Health, 17, 485-491. http://dx.doi.org/10.1016/j.paed.2007.09.006

[14] Cook, G.C. (1991) Tropical Medicine. Postgraduate Medical Journal, 67, 798-822. http://dx.doi.org/10.1136/pgmj.67.791.798

[15] Cleland, J.G., Ndugwa, R.P. and Zulu, E.M. (2011) Family Planning in Sub-Saharan Africa: Progress or Stagnation? Bulletin of the World Health Organization, 89, 137-143. http://dx.doi.org/10.2471/BLT.10.077925

[16] Cleland, J., Bernstein, S., Ezeh, A., Faundes, A., Glasier, A. and Innis, J. (2006) Family Planning: The Unfinished Agenda. Lancet, 368, 1810-1827. http://dx.doi.org/10.1016/S0140-6736(06)69480-4 
[17] Babalola, S., Vondrasek, C., Brown, J. and Traore, R. (2001) The Impact of a Regional Family Planning Service Promotion Initiative in Sub-Saharan Africa: Evidence from Cameroon. International Family Planning Perspectives, 27, 186-193. http://www.jstor.org/stable/2673854

http://dx.doi.org/10.2307/2673854 